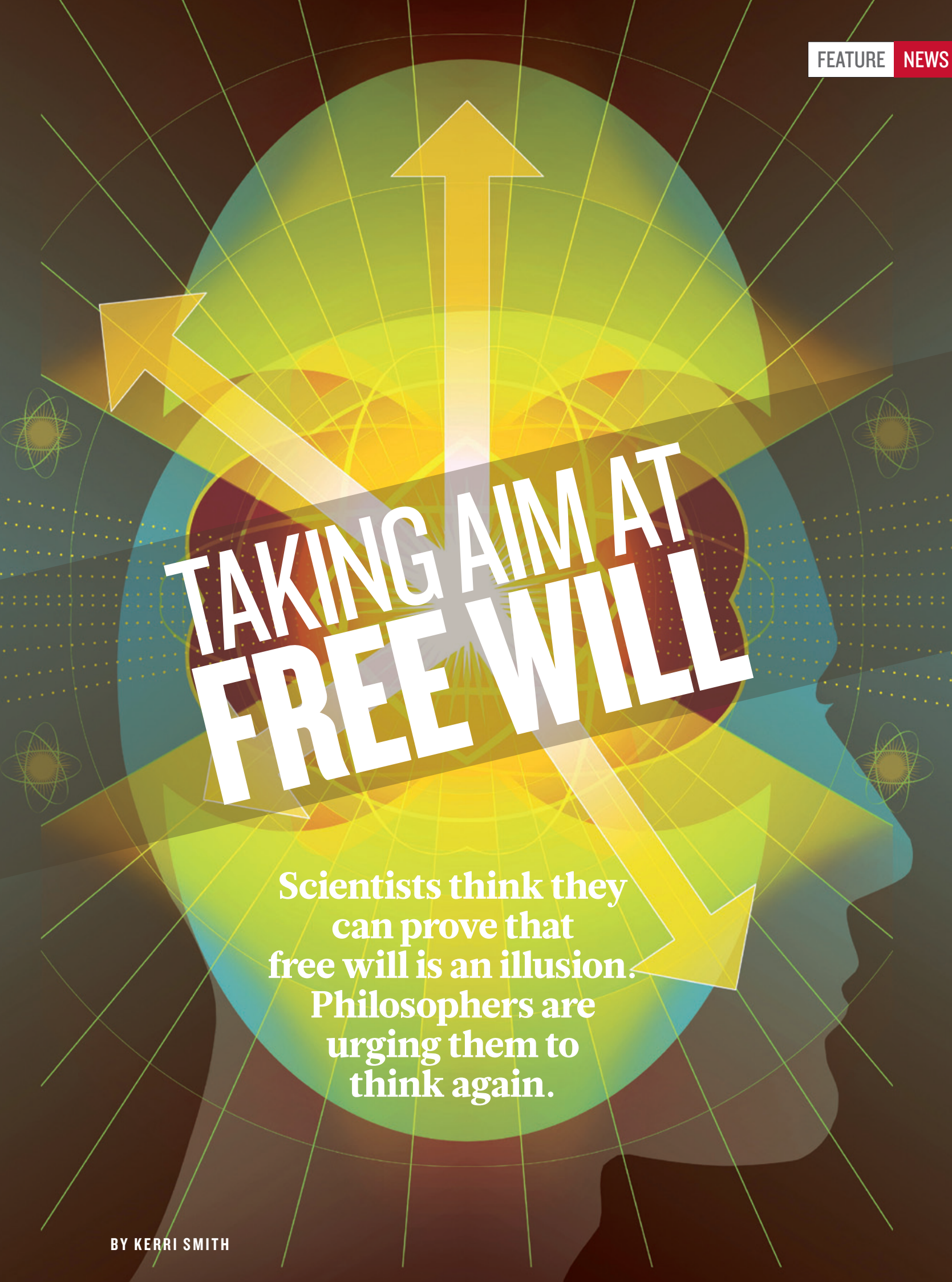

THE EXPERIMENT HELPED TO CHANGE JOHN-DYLAN HAYNES'S OUTLOOK ON LIFE. In 2007, Haynes, a neuroscientist at the Bernstein Center for Computational Neuroscience in Berlin, put people into a brain scanner in which a display screen flashed a succession of random letters ${ }^{1}$. He told them to press a button with either their right or left index fingers whenever they felt the urge, and to remember the letter that was showing on the screen when they made the decision. The experiment used functional magnetic resonance imaging (fMRI) to reveal brain activity in real time as the volunteers chose to use their right or left hands. The results were quite a surprise. 
- "The first thought we had was "we have to check if this is real'," says Haynes. "We came up with more sanity checks than I've ever seen in any other study before."

The conscious decision to push the button was made about a second before the actual act, but the team discovered that a pattern of brain activity seemed to predict that decision by as many as seven seconds. Long before the subjects were even aware of making a choice, it seems, their brains had already decided.

As humans, we like to think that our decisions are under our conscious control - that we have free will. Philosophers have debated that concept for centuries, and now Haynes and other experimental neuroscientists are raising a new challenge. They argue that consciousness of a decision may be a mere biochemical afterthought, with no influence whatsoever on a person's actions. According to this logic, they say, free will is an illusion. "We feel we choose, but we don't," says Patrick Haggard, a neuroscientist at University College London.

You may have thought you decided whether to have tea or coffee this morning, for example, but the decision may have been made long before you were aware of it. For Haynes, this is unsettling. "I'll be very honest, I find it very difficult to deal with this," he says. "How can I call a will 'mine' if I don't even know when it occurred and what it has decided to do?"

\section{THOUGHT EXPERIMENTS}

Philosophers aren't convinced that brain scans can demolish free will so easily. Some have questioned the neuroscientists' results and interpretations, arguing that the researchers have not quite grasped the concept that they say they are debunking. Many more don't engage with scientists at all. "Neuroscientists and philosophers talk past each other," says Walter Glannon, a philosopher at the University of Calgary in Canada, who has interests in neuroscience, ethics and free will.

There are some signs that this is beginning to change. This month, a raft of projects will get under way as part of Big Questions in Free Will, a four-year, US\$4.4-million programme funded by the John Templeton Foundation in West Conshohocken, Pennsylvania, which supports research bridging theology, philosophy and natural science. Some say that, with refined experiments, neuroscience could help researchers to identify the physical processes underlying conscious intention and to better understand the brain activity that precedes it. And if unconscious brain activity could be found to predict decisions perfectly, the work really could rattle the notion of free will. "It's possible that what are now correlations could at some point become causal connections between brain mechanisms and behaviours," says Glannon. "If that were the case, then it would threaten free will, on any definition by any philosopher."
Haynes wasn't the first neuroscientist to explore unconscious decision-making. In the 1980s, Benjamin Libet, a neuropsychologist at the University of California, San Francisco, rigged up study participants to an electroencephalogram (EEG) and asked them to watch a clock face with a dot sweeping around it $^{2}$. When the participants felt the urge to move a finger, they had to note the dot's position. Libet recorded brain activity several hundred milli-

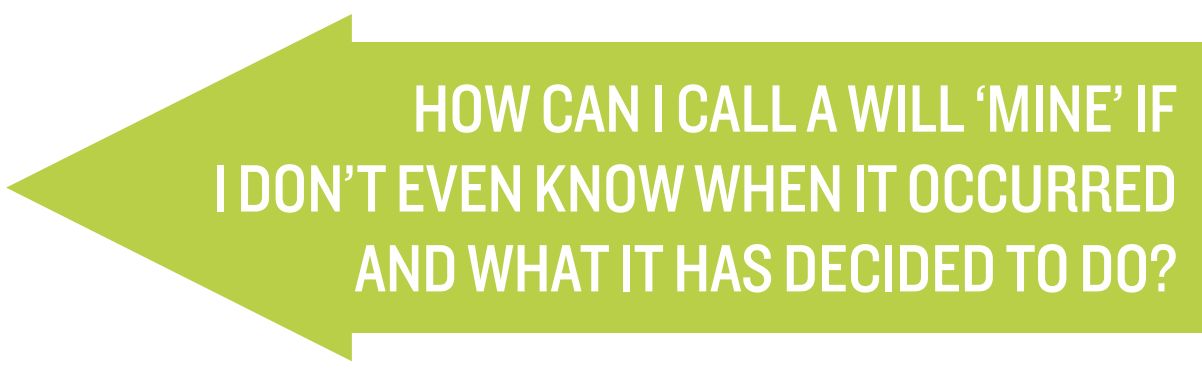

seconds before people expressed their conscious intention to move.

Libet's result was controversial. Critics said that the clock was distracting, and the report of a conscious decision was too subjective. Neuroscience experiments usually have controllable inputs - show someone a picture at a precise moment, and then look for reactions in the brain. When the input is the participant's conscious intention to move, however, they subjectively decide on its timing. Moreover, critics weren't convinced that the activity seen by Libet before a conscious decision was sufficient to cause the decision - it could just have been the brain gearing up to decide and then move.

Haynes's 2008 study $^{1}$ modernized the earlier experiment: where Libet's EEG technique could look at only a limited area of brain activity, Haynes's fMRI set-up could survey the whole brain; and where Libet's participants decided simply on when to move, Haynes's test forced them to decide between two alternatives. But critics still picked holes, pointing out that Haynes and his team could predict a left or right button press with only $60 \%$ accuracy at best. Although better than chance, this isn't enough to claim that you can see the brain making its mind up before conscious awareness, argues Adina Roskies, a neuroscientist and philosopher who works on free will at Dartmouth College in Hanover, New Hampshire. Besides, "all it suggests is that there are some physical factors that influence decision-making", which shouldn't be surprising. Philosophers who know about the science, she adds, don't think this sort of study is good evidence for the absence of free will, because the experiments are caricatures of decision-making. Even the seemingly simple decision of whether to have tea or coffee is more complex than deciding whether to push a button with one hand or the other.

Haynes stands by his interpretation, and has replicated and refined his results in two studies.
One uses more accurate scanning techniques ${ }^{3}$ to confirm the roles of the brain regions implicated in his previous work. In the other, which is yet to be published, Haynes and his team asked a series being presented on a screen. Deciding whether to add or subtract reflects a more complex intention than that of whether to push a button, and Haynes argues that it is a more realistic model for everyday decisions. Even in subjects to add or subtract two numbers from this more abstract task, the researchers detected activity up to four seconds before the subjects were conscious of deciding, Haynes says.

Some researchers have literally gone deeper into the brain. One of those is Itzhak Fried, a California, Los Angeles, and the Tel Aviv Medical Center in Israel. He studied individuals with electrodes implanted in their brains as part of a surgical procedure to treat epilepsy ${ }^{4}$. Recording from single neurons in this way gives scientists a much more precise picture of brain activity than fMRI or EEG. Fried's experiments showed that there was activity in individual neurons of particular brain areas about a second and a half before the subject made a conscious decision to press a button. With about 700 milliseconds to go, the researchers could predict the timing of that decision with more than $80 \%$ accuracy. "At some point, things that are predetermined are admitted into consciousness," says Fried. The conscious will might be added on to a decision at a later stage, he suggests.

\section{MATERIAL GAINS}

Philosophers question the assumptions underlying such interpretations. "Part of what's driving some of these conclusions is the thought that free will has to be spiritual or involve souls or something," says Al Mele, a philosopher at Florida State University in Tallahassee. If neuroscientists find unconscious neural activity that drives decision-making, the troublesome concept of mind as separate from body disappears, as does free will. This 'dualist' conception of free will is an easy target for neuroscientists to knock down, says Glannon. "Neatly dividing mind and brain makes it easier for neuroscientists to drive a wedge between them," he adds.

The trouble is, most current philosophers don't think about free neuroscientist and surgeon at the University of
DNATURE.COM To listen to a podcast about neuroscience and free will, visit: go.nature.com/ihlh5z 
will like that, says Mele. Many are materialists - believing that everything has a physical basis, and decisions and actions come from brain activity. So scientists are weighing in on a notion that philosophers consider irrelevant.

Nowadays, says Mele, the majority of philosophers are comfortable with the idea that people can make rational decisions in a deterministic universe. They debate the interplay between freedom and determinism - the says. Some informal meetings have already begun. Roskies, who is funded through the programme, plans to spend time this year in the lab of Michael Shadlen, a neurophysiologist at the University of Washington in Seattle who works on decision-making in the primate brain. "We're going to hammer on each other until we really understand the other person's point of view, and convince one or other of us that we're wrong," she says.
Foundation in Chicago, Illinois, suggests that the research could help to identify an individual's level of responsibility. "What we are interested in is how neuroscience can give us a more granulated view of how people vary in their ability to control their behaviour," says Jones. That could affect the severity of a sentence, for example.

The answers could also end up influencing people's behaviour. In 2008, Kathleen Vohs, a social psychologist at the University of Minnesota in Minneapolis, and her colleague Jonathan Schooler, a psychologist now at the University of California, Santa Barbara, published a study ${ }^{5}$ on how people behave when they are prompted to think that determinism is true. They asked their subjects to read one of two passages: one suggesting that behaviour boils down to environmental or genetic factors not under personal control; the other neutral about what influences behaviour. The participants then did a few maths problems on a computer. But just before the test started, they were informed that because of a glitch in the computer it occasionally displayed the answer by accident; if this happened, they were to click it away without looking. Those who had read the deterministic message were more likely to cheat on the test. "Perhaps, denying free will simply provides the ultimate excuse to behave as one likes," Vohs and Schooler suggested.

Haynes's research and its possible implications have certainly had an effect on how he thinks. He remembers being on a plane on his way to a conference and having an epiphany. "Suddenly I had this big vision about the whole deterministic universe, myself, my place in it and all these different points where we believe we're making decisions just reflecting some causal flow." But he couldn't maintain this image of a world without free will for long. "As soon as you start interpreting people's behaviours in your day-to-day life, it's virtually impossible to keep hold of," he says.

Fried, too, finds it impossible to keep determinism at the top of his mind. "I don't think about it every day. I certainly don't think about it when I operate on the human brain."

Mele is hopeful that other philosophers will become better acquainted with the science of conscious intention. And where philosophy is concerned, he says, scientists would do well to soften their stance. "It's not as though the task of neuroscientists who work on free will has to be to show there isn't any."

Kerri Smith is editor of the Nature Podcast, and is based in London.

1. Soon, C. S., Brass, M., Heinze, H.-J. \& Haynes, J.-D. Nature Neurosci. 11, 543-545 (2008).

2. Libet, B., Gleason, C. A., Wright, E. W. \& Pearl, D. K Brain 106, 623-642 (1983).

3. Bode, S. et al. PLoS ONE 6, e21612 (2011).

4. Fried, I., Mukamel, R. \& Kreiman, G. Neuron 69, 548-562 (2011).

5. Vohs, K. D. \& Schooler, J. W. Psychol. Sci. 19, 49-54 (2008). we'll get better evidence about what goes on in the brain when people make decisions," he
Owen Jones, a law professor at Vanderbilt University in Nashville, Tennessee, who directs a similar project funded by the MacArthur 